\title{
The Use of Radar Technologies in the Trace Engineering
}

\author{
Zhanar Oralbekova ${ }^{1, *}$, Dinara Omarkhanova ${ }^{1, *}$, Makpal Zhartybayeva ${ }^{1}$, Alma Zakirova ${ }^{1}$ and Baktygerei \\ Sholpanbaev ${ }^{2}$
}

1 L.N. Gumilyov Eurasian National University; oralbekova@mail.ru (Z.O.), dinara.omarkhanova@mail.ru (D.O.), makkenskii@mail.ru (M.Z.), alma_zakirova@mail.ru (A.Z.)

2 Joldasbekov Institute of Mechanics and Engineering; bahtygerey@mail.ru

* Correspondence: oralbekova@mail.ru (Z.O.), dinara.omarkhanova@mail.ru (D.O.); Tel.: +77072502428 (Z.O.), +7708159591 (D.O.)

\begin{abstract}
The paper presents experimental studies on the geophysical survey of Almaty - Nur-Sultan highway sections, which located $100 \mathrm{~km}$. from Almaty, Almaty region of the Republic of Kazakhstan. As the object of study selected highway sections in 3 places: on the highway section with a well-preserved coating to identify layers; on the highway section with obvious damage (with holes, potholes, horizontal and grid cracks); on the section of the highway with a drainage pipe. Since the formulation of the problem requires the use of a non-destructive, fast method that gives an idea of the layer structures with an accuracy of $\pm 0.1 \mathrm{~m}$., experimental studies were conducted using the ground penetrating radar (GPR) «Loza B» using different antennas, with different profile steps for accuracy. The results of the geophysical survey of the structure of the underlying layers and asphalt for the detection of defects and their causes are presented. The results of this work can be used to develop compositions of asphalt concrete mixtures with high temperature stability, strength and durability, considering the climatic conditions in order to ensure the safety of road surfaces during operation.
\end{abstract}

Keywords: interpretation of radarograms, experimental researches, ground penetrating radar

\section{Introduction}

Subsurface object radar is used for non-destructive testing and diagnostics of objects in the field of construction, archeology, geology, geophysics, and customs control [1-4]. Currently, subsurface radar devices (GPR) are used for diagnostics. There are various modifications of the devices that have found wide commercial application [5-15]. In our country, in practice, there is an experience of using ground-penetrating radars produced in such countries as Russia and Latvia [16-21]. However, the existing embedded software of GPR does not sufficiently describe the methods for determining the geoelectric properties of the objects under study, since these built in programs are commercial in nature. The result of this work is a contribution to the development of methods for interpreting GPR data and can be further used to develop compositions of asphalt concrete mixtures with high temperature stability, strength and durability, taking into account the climatic conditions and the preparation of the underlying environment - the base of the road with different soils and water content.

The following 3 sections (parts) of the road were selected as the object of study:

1. The highway section with well-preserved covering a length of 44 meters.

2. The highway section with obvious damages (with holes, potholes, horizontal and grid cracks), about 47 meters long.

3. The highway section with a drain pipe a length of 30 meters. 
Purpose: to test the proposed method on the example of GPR research of the internal structure of Almaty - Nur-Sultan highway construction on the section which is 100 kilometers away from the city of Almaty in the Almaty region of the Republic of Kazakhstan.

\section{Materials and Methods}

Statement of the problem requires the use of non-destructive, fast method that gives an idea of the structure of the layers with an accuracy of $\pm 0.1 \mathrm{~m}$. The principle of operation of ground-penetrating radars is based on the emission of ultra-wideband high-frequency electromagnetic pulses into the probed medium and receiving reflected signals from heterogeneities and objects in the thickness of the medium. The received information is recorded in the GPR memory and represents a GPR profile with the necessary degree of detail of the depth of occurrence and the physical composition of layers and inclusions. Such a method is a method of non-destructive testing and control [22].

Experimental studies were performed by the geophysical complex "Loza B" using a $1.5 \mathrm{~m}$. antenna $(150 \mathrm{MHz})$, a $0.2 \mathrm{~m}$. profile step on the first route of the first section of the road (marked with a green arrow in Figure 1), using an antenna 1m.(100 MHz) in 0,1m. increments along the second route of the first section of the highway, indicated in Figure 1 with a blue arrow; using an antenna $1 \mathrm{~m}$. $(100 \mathrm{MHz}), 0.1 \mathrm{~m}$. profile step. along the first route of the second section of the highway (marked in figure 1 with a red arrow), using a $0.5 \mathrm{~m}$. antenna $(50 \mathrm{MHz})$ in increments of $0.05 \mathrm{~m}$. along the second route of the second section of the highway indicated in Figure 1 with a yellow arrow; using an antenna $1 \mathrm{~m}$. $(100 \mathrm{MHz})$, a step along the profile of $0.2 \mathrm{~m}$. on the road of the third section of thehighway (marked in Figure 1 with a gray arrow).

a) the $1^{\text {st }}$ route of the $1^{\text {st }}$ section of the highway, step $0,2 \mathrm{M}$

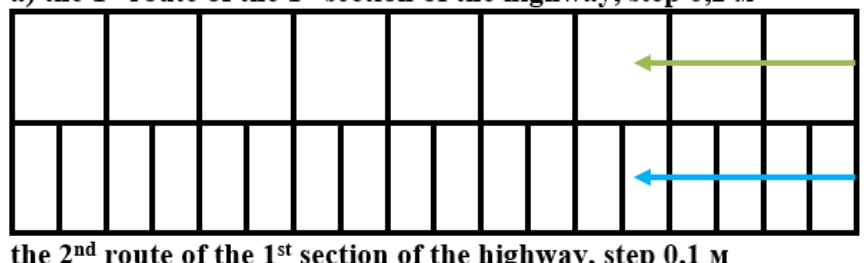

б) the $1^{\text {st }}$ route of the $2^{\text {nd }}$ section of the highway, step $0,1 \mathrm{M}$

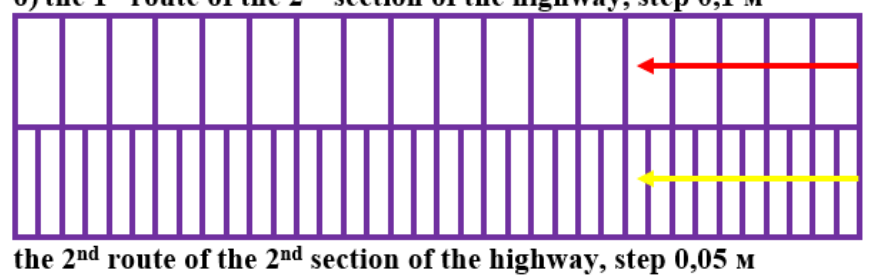

c) the route of the $3^{\text {rd }}$ section of the highway, step $0,2 \mathrm{M}$

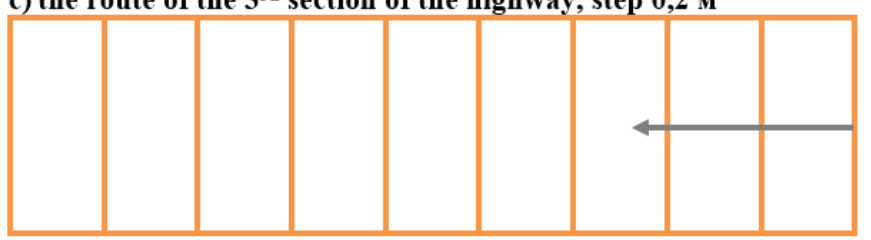

Figure 1. The scheme oftrace: a) the $1^{\text {st }}$ highway section with well-preserved coverage;

b) the $2^{\text {nd }}$ highway section with obvious damage; c) the $3^{\text {rd }}$ highway section with drainage pipe.

In experimental studies, we used the following method: profiling with separate profiles with different antennas for accuracy. The use of geo-radar profiling shows that the successful solution of problems is significantly influenced by a combination of actual circumstances, conditions and reasons. GPR measurements are carried out along the profile. The profile is the radarogram, the imaginary line that we followed on the surface of the earth with our measurements. Laying profiles and selecting the speed of movement along the profile or the step between the observation points is the planning stage. GPR profiling 
is the definition of the spatial characteristics of objects and the definition of the types of these objects. The GPR begins to write a graph that depends on the time and amplitude of the signals. Each track is restored at several points. You can go from time to depth parameters by learning the physical property of the environment. The depth of research is the maximum depth of the reflecting object. Therefore, much attention is paid to the assessment of the depth of GPR [22, 23].

The used antennas provide the possibility of probing in the frequency range (50-150 $\mathrm{MHz}$ ). The use of a particular antenna is determined by the problem we solve when probing. The increasing frequency of the sensing leads to the improvement in resolution, it also increases the attenuation of electromagnetic waves in the environment, which leads to a decrease of probing depth and Vice versa, a decrease in the frequency is possible to increase the depth sensing, but it deteriorates the resolution. In addition, with a decrease in frequency, the zone of initial insensitiveness (dead zone) of the GPR increases. The antennas used provide the possibility of sensing in the frequency range (50-150 MHz). The use of a particular antenna is determined by the problem we solve when probing.

Also, in GPR research, the shooting step plays an important role. It depends on the step whether the study is correct and whether we can make an interpretation of the data. The manufacturer's recommended pitch for small objects such as pipes, cables, and trenches is no more than $0.2 \mathrm{~m}$. If the distance is greater, the profile will be uninformative and there may be difficulties in interpreting the data. In this regard, different steps were chosen for the experiment for different sections of the highway. All technical characteristics and features of using this geophysical instrument are described in [24].

\section{Results}

GPR "Loza B" has a embedded software called "Krot179Ns" [9]. As a result of the "Krot179Ns" program in Figure 2, the profile of the first trace is shown, which is in Figure 1 is marked with a green arrow.

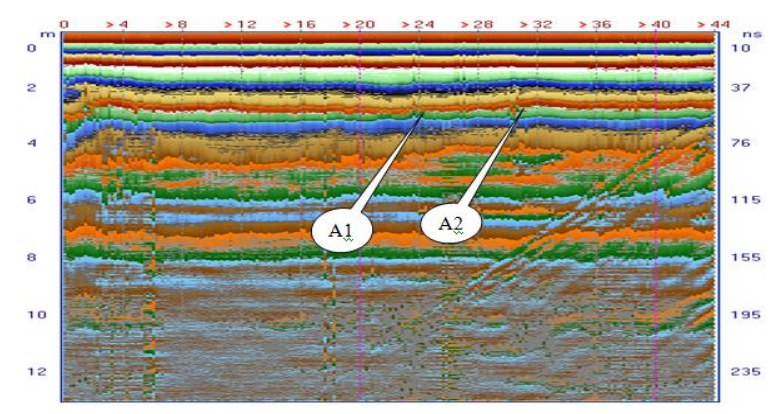

Figure 2. The profile of the trace with a step of $0.2 \mathrm{~m}$. with the distance between the antennas $1.5 \mathrm{~m}$.

Figure 3 shows the profile of the second trace, which is shown in Figure 1 is marked with a blue arrow.

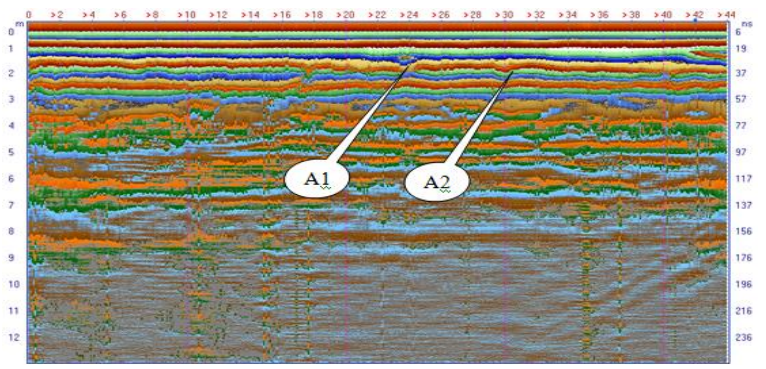

Figure 3. Profile of the $2^{\text {nd }}$ trace with a step of $0.1 \mathrm{~m}$. , distance between antennas of $1 \mathrm{~m}$. 
On the radarograms of two different antennas, the layers appear flat with small irregularities in the lower layers that coincide in two dimensions (pointers A1 and A2 in Figure 2 and Figure 3). Figures 4-5 show similar figures (GPR profiles) for the traces on the second section of the highway.

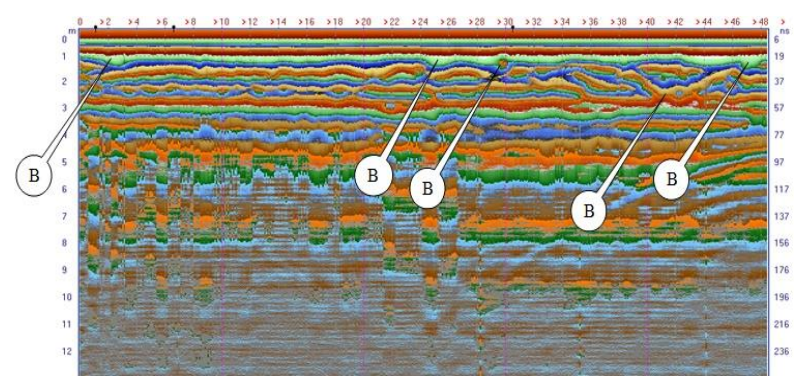

Figure 4. Profile of the first measurement of the second section highway with a 1-meter antenna with a step of $0.1 \mathrm{~m}$.

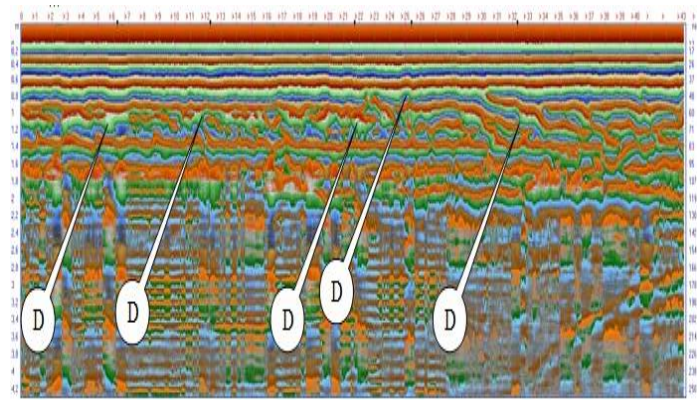

Figure 5. Profile of the $2^{\text {nd }}$ measurement of the $2^{\text {nd }}$ section highway with a $0.5 \mathrm{~m}$. antenna with a step of $0.05 \mathrm{~m}$.

Figure 6 shows the trace profile of the third section highway.

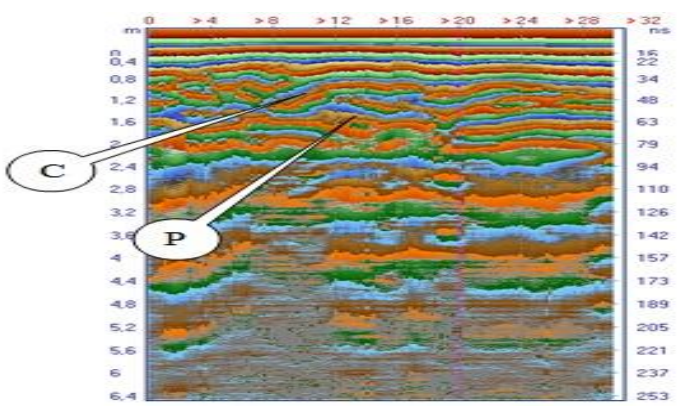

Figure 6 . The trace profile of the $3^{\text {rd }}$ section highway with a step of $0.1 \mathrm{~m}$., the distance between the antennas is $1 \mathrm{~m}$.

A concrete pipe is observed on the third section (Figure 6, pointer P) with a concrete ceiling (Figure 6, pointer C).

\section{Discussion}

In both measurements of the 2-section highway, there are obvious anomalies (moistening, subsidence, etc.) in the lower layers, which are then reflected on the upper layer (asphalt) in the form of holes, hollows, horizontal and grid cracks. Figure 4 shows anomalies in the underlying layers (pointers B). Also visible as bottom layers overlap and blend in places. The lower boundary of the sandy base is expressed non-contrast. When measuring, problem areas on asphalt were marked with marks that correspond to anomalies on the lower layers (Figure 5, pointers D). 
Figure 7 shows the identified layers of the road under study with a depth of $2 \mathrm{~m}$.: asphalt, underlying layers (crushed stone, embankments, irregularities), bulk soil, base.

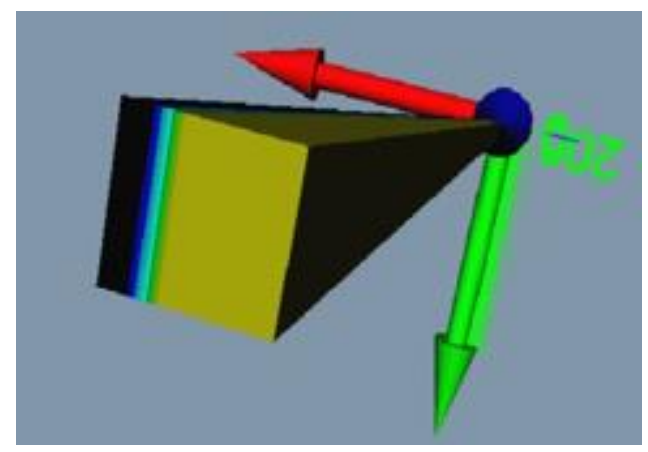

Figure 7. Layers of the road

The obtained GPR data were imported into MSExcel, which will later be used as input data for solving the inverse geoelectrics problem by the layer-by-layer recalculation method [25]. The environment model is layered.

\section{Conclusions}

In this work, the first section of the road with a good road surface was chosen as a reference. On the second section of the road, there are many anomalies associated with displacement and changes in the flatness of the layers, which is observed on the upper asphalt layer as pits, potholes, horizontal and grid cracks. The change in the lower layers of the second section is due to waterlogging. The presence of a pipe under the asphalt is the cause of the defect on the third section of the highway.

It should be noted that the proposed method was used by us at another facility, for the diagnosis of subsurface runway coverings, and gave good results [16].

In further research, the obtained GPR data for the second section of the highway will be used as input data for solving the inverse coefficient problem of geoelectrics which is described in [25].

The results of this work can be used to develop compositions of asphalt concrete mixtures with high temperature stability, strength and durability, considering the climatic conditions of the Republic of Kazakhstan in order to ensure the safety of road surfaces during operation.

Author Contributions: Conceptualization, Z.O. and B.S.; methodology, Z.O.; validation, D.O., A.Z. and B.S.; formal analysis, M.Z.; investigation, D.O.; resources, B.S.; data curation, B.S.; writingoriginal draft preparation, M.Z.; writing - review and editing, D.O.; visualization, A.Z.; supervision, Z.O.; project administration, Z.O. All authors have read and agreed to the published version of the manuscript.

Funding: This research was funded by by the Ministry of Education and Science of the Republic of Kazakhstan, under the Grant No. 132, 12 March 2018 (IRN: AP05133922).

Conflicts of Interest: The authors declare no conflict of interest.

\section{References}

1. Leon L.P., Jr.; Young, J.D.; Daniels, J.J. Ground penetrating radar as a subsurface environmental sensing tool, Proceedings of the IEEE 1994, vol. 82, no. 12, pp.1802-1822. DOI 10.1109/5.338072

2. Daniels, D.J. Surface-Penetrating Radar, 2nd ed.; The Institution of Electrical Engineers: London, United Kingdom, 2004; pp.1-761. 
3. Vitebskiy, S.; Carin, L.; Ressler, M.A.; Le, F.H. Ultra-wideband, short-pulse ground-penetrating radar: simulation and measurement, IEEE Transactions on Geoscience and Remote Sensing 1997, vol. 35, no. 3, pp. 762-772. DOI $10.1109 / 36.581999$

4. Carin, L.; Geng, N.; McClure, M.; Sichina, J.; Nguyen, L. Ultra-wide-band synthetic-aperture radar for minefield detection, IEEE Antennas and Propagation Magazine 1999, vol. 41, no. 1, pp. 18-33. DOI 10.1109/74.755021

5. Arcone, S.A.; Lawson, D.E.; Delaney, A.J. Ground-Penetrating Radar Reflection Profiling of Groundwater and Bedrock in An Area of Discontinuous Permafrost. Geophysics 1998, vol. 63, pp. 1573-1584. DOI 10.1190/1.1444454

6. Arcone, S.A.; Prentice, M.L.; Delaney, A.J. Stratigraphic Profiling with Ground-Penetrating Radar in Permafrost: A Review of Possible Analogs for Mars. J. Geophys. Res. 2002, vol. 107, pp. 1-14. DOI 10.1029/2002je001906

7. Xiao, J.; Liu, L. Signal Fusion Using Extrapolation with Deterministic Deconvolution on Multi-Frequency Qinghai-Tibet Railway GPR Data for Permafrost Subgrade Detection. In Proceedings of the 15th International Conference on Ground Penetrating Radar, Brussels, Belgium, 30 June-4 July 2014; pp. 586-589.

8. Shen, Y.; Lin, Y.; Li, P.; Fu, Y.; Wang, Y. Simulation and detection leakage of underground water pipeline by ground penetrating radar, Journal of Testing and Evaluation 2019, vol. 48(3): 20190181 DOI:10.1520/JTE20190181

9. Dorn, C.; Linde, N.; Doetsch, J.; Le Borgne, T.; Bour, O. Fracture imaging within a granitic rock aquifer using multiple-offset single-hole and cross-hole GPR reflection data. J. Appl. Geophys. 2012, vol. 78, pp. 123-132.

10. Keskinen, J.; Klotzsche, A.; Looms, M.C.; Moreau, J.; van der Kruk, J.; Holliger, K.; Stemmerik, L.; Nielsen, L. Full-waveforminversion of crosshole GPR data: Implications for porosity estimation in chalk. J. Appl. Geophys. 2017, vol. 140, pp. 102-116. DOI 10.1016/j.jappgeo.2017.01.001

11. Liu, S.; Liu, X.; Meng, X.; Fu, L.; Lu, Q.; Deng, L. Application of time-domain full waveform inversion to crosshole radar data measured at Xiuyan jade mine, China. Sensors 2018, Vol. 18, 3114. DOI 10.3390/s18093114

12. Hu, S.F.; Zhao, Y.H.; Rao, C.F.; Qin, T.; An, C.; Ge, S.C. GPR tomography based on regularization method for concrete defect detection. In Proceedings of the 16th International Conference on Ground Penetrating Radar (GPR), Hong Kong, China, 13-16 June 2016; pp. 1-6.

13. Qin, H.; Xie, X.; Tang, Y.; Wang, Z. Detection of diaphragm wall defects using crosshole GPR. In Proceedings of the 17th International Conference on Ground Penetrating Radar, Rapperswil, Switzerland, 18-21 June 2018; pp. 1-4.

14. Lai, W.W.L.; Dérobert, X.; Annan, P. A review of ground penetrating radar application in civil engineering: A 30-year journey from locating and testing to imaging and diagnosis. NDT E Int. 2018, vol. 96, pp. 58-78. DOI 10.1016/j.ndteint.2017.04.002

15. Belashev, B.Z.; Nilov, M.Yu. Georadar data processing by an automatic algorithm. Proceedings of the Karelian Research Centre of the Russian Academy of Sciences 2020, vol. 7, pp. 19-27. DOI:10.17076/mat1221

16. Zhartybayeva, M.; Oralbekova, Z.; Iskakov K. The Interpretation of the Radarograms on the Basis of Experimental Data, Acta Physica Polonica 2015, vol. 128(2), pp. 467-468. DOI 10.12693/APhysPolA.128.B-467

17. Kabanikhin, S.I.; Nurseitov, D.B.; Shishlenin, M.A.; Sholpanbaev, B.B. Inverse problems for the ground penetrating radar, Journal of Inverse and Ill-Posed Problems 2013, vol. 21(6), pp. 885-892. DOI 10.1515/jip-2013-0057

18. Iskakov, K.; Boranbayev, S.; Alimbayeva, Z.; Issin, B. Experimental data of research using ground-penetrating radar Zond-12c and interpretation of georadarograms, Acta Physica Polonica A 2016, vol. 130(1), pp. 322-324. DOI:10.12693/APhysPolA.130.322

19. Uzakkyzy, N.; Iskakov, K.; Boranbayev, S. About the results of the processing route radarogram Haar wavelets and Daubechies, Progress in Electromagnetics Research Symposium, St. Petersburg, Russia, 22-25 May 2017; pp. 37293739. DOI 10.1109/PIERS.2017.8262406

20. Iskakov, K.T.; Boranbaev, S.A.; Uzakkyzy, N. Wavelet processing and filtering of the radargram trace, Eurasian journal of Mathematical and Computer Applications 2017, vol. 5(4), pp. 43-54. DOI 10.32523/2306-3172-2017-5-4-43-54 
21. Iskakov, K.T.; Tokseit, D.K.; Oralbekova, Z.O.; Mirgalikyzy, T. Creation and testing of a new mathematical software for processing georadar data, Eurasian Journal of Mathematical and Computer Applications 2019, vol. 7(4), pp.8699. DOI 10.32523/2306-3172-2017-5-4-43-54

22. Vladov, M.L.; Starovoitov, A.V. Introduction to ground penetrating radar. MSU Publishing House: Moscow, Russia, 2004; pp.1-153.

23. Özdemir, C.; Demirci, Ş; Yiğit, E; Yilmaz, B. A Review on Migration Methods in B-Scan Ground Penetrating Radar Imaging, Mathematical Problems in Engineering 2014, Article ID 280738, 16 pages. DOI 10.1155/2014/280738

24. Serzhanov, A.B.; Zhartybaeva M. Detection features and physical characteristics of the source signal and the receiver via devices "Eniks-01" and "Loza B". BULLETIN of L.N. Gumilyov Eurasian National University 2014 , vol. 6(103), pp. 186-190.

25. Karchevsky, A.L. Simultaneous reconstruction of permittivity and conductivity, Journal of Inverse and Ill-Posed Problems 2009, vol.17(4), pp. 387-404. DOI 10.1515/JIIP.2009.026 